\title{
The SLCO1A2 -189_-188InsA polymorphism reduces clearance of rocuronium in patients submitted to elective surgeries
}

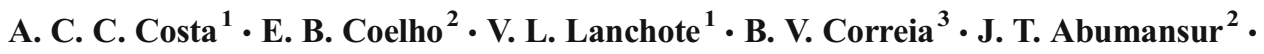 \\ G. R. Lauretti ${ }^{2} \cdot$ N. V. de Moraes $^{3}$
}

Received: 31 January 2017 / Accepted: 22 March 2017 / Published online: 14 April 2017

(C) Springer-Verlag Berlin Heidelberg 2017

\begin{abstract}
Purpose Rocuronium (ROC) is a neuromuscular blocker mainly eliminated by biliary excretion dependent on organic anion transporting polypeptide 1A2 (OATP1A2) hepatocellular uptake. However, the influence of SLCO1A2 (gene encoding OATP1A2) genetic polymorphism on ROC pharmacokinetics was never described before. The objective of this work was to evaluate the influence of genetic polymorphisms of SLCO1A2 on the pharmacokinetics of rocuronium (ROC). Methods Patients undergoing elective surgeries under general anesthesia using rocuronium as a neuromuscular blocker were genotyped for SLCO1A2 polymorphisms in the coding region $(41 \mathrm{~A}>\mathrm{G}, 382 \mathrm{~A}>\mathrm{T}, 404 \mathrm{~A}>\mathrm{T}, 502 \mathrm{C}>\mathrm{T}, 516 \mathrm{~A}>\mathrm{C}, 559 \mathrm{G}>\mathrm{A}$, $830 \mathrm{C}>\mathrm{A}$, and $833 \mathrm{delA}$ ) and in the promoter region ($1105 \mathrm{G}>\mathrm{A},-1032 \mathrm{G}>\mathrm{A},-715 \mathrm{~T}>\mathrm{C},-361 \mathrm{G}>\mathrm{A}$, and -189 188insA). Rocuronium pharmacokinetic parameters were estimated by non-compartmental analysis.

Results None of the patients had heterozygous or homozygous variant of $404 \mathrm{~A}>\mathrm{T}, 382 \mathrm{~A}>\mathrm{T}, 502 \mathrm{C}>\mathrm{T}, 833 \mathrm{delA}$, $830 \mathrm{C}>\mathrm{A}, 41 \mathrm{~A}>\mathrm{G}$, and $-715 \mathrm{~T}>\mathrm{C}$. A linkage disequilibrium was found between $-1105 \mathrm{G}>\mathrm{A}$ and $-1032 \mathrm{G}>\mathrm{A}$ genotypes. Patients genotyped as -A or AA $(n=17)$ for SLCO1A2 -
\end{abstract}

N. V. de Moraes

nmoraes@fcfar.unesp.br

1 Universidade de São Paulo (USP), Faculdade de Ciências Farmacêuticas de Ribeirão Preto, Ribeirão Preto, SP, Brazil

2 Universidade de São Paulo (USP), Faculdade de Medicina de Ribeirão Preto, Ribeirão Preto, SP, Brazil

3 Universidade Estadual Paulista (UNESP), Faculdade de Ciências Farmacêuticas, Araraquara, SP, Brazil
189 -188InsA showed reduced total clearance of ROC compared to patients genotyped as $-/-(n=13)(151.6 \mathrm{vs}$ $207.1 \mathrm{~mL} / \mathrm{min}, p \leq 0.05$ ). The pharmacokinetics parameters of ROC were not significantly different between other SLCO1A2 genotypes.

Conclusion SLCO1A2 -189_-188InsA polymorphism is related to the reduced clearance of rocuronium in patients submitted to elective surgeries under general anesthesia.

Trial registration NCT 02399397 (ClinicalTrials.gov)

Keywords Pharmacogenetics $\cdot$ Rocuronium ·

Neuromuscular blockade $\cdot$ SNPs $\cdot$ Pharmacokinetics

\section{Introduction}

The organic anion transporting polypeptide 1A2 (OATP1A2), also known as human OATP-A or OATP1, mediates the cellular uptake of endogenous compounds and a variety of drugs. OATP1A2, encoded by SLCO1A2 gene, is expressed in blood-brain barrier, distal nephrons, and in the apical membrane of bile duct cells (cholangiocytes) in the liver. The expression of OATP1A2 in these different tissues suggests its relevance to different processes of drug kinetic disposition such as drug distribution to the central nervous system, renal excretion, metabolism, and biliary excretion [1-4]. The list of OATP1A2 substrates includes endogenous substances, for instance bile acids, thyroid and steroid hormones, and drugs, e.g., statins, methotrexate, fexofenadine, imatinib, and HIV protease inhibitors. In vitro studies with cell transfected with SLCO1A2 have contributed significantly to the identification of substrates and to characterize the functional relevance of this transporter in pharmacokinetics [5, 6]. 
Rocuronium (ROC) is a neuromuscular blocker often used during general anesthesia to facilitate endotracheal intubation, artificial ventilation, and surgical procedures. It is mainly eliminated as the unchanged drug by biliary excretion depending on the hepatocellular uptake by OATP1A2, but also by renal excretion, while the metabolism of ROC is practically absent [5-7]. The distribution of ROC to the liver is considered a determining factor for the duration of neuromuscular blockade. The concentration of ROC in bile ranged from 2 to $1217 \mu \mathrm{g} / \mathrm{mL}$ (median = $377 \mathrm{mg} / \mathrm{mL}$ ), while bile/plasma concentration ratio ranged from 130 to 2800 (median $=400)$ in ASA (American Society of Anesthesiology) classification IIII patients undergoing surgery under general anesthesia [7]. Rocuronium fraction unbound in plasma determined by ultrafiltration was 0.54 [8].

A large inter-individual variability in drug disposition and response results from the complex interaction between demographic, clinical, genetic, and environmental factors. Age, renal function, liver function, and race were already described as covariates to the pharmacokinetics of ROC [9]. Patients with renal impairment (ASA II-III, creatinine clearance $<30 \mathrm{~mL} /$ min) showed a fourfold reduction in the total clearance of ROC when compared to healthy patients (ASA I-II) [10]. Reduction in ROC clearance was also observed in cirrhotic patients when compared to healthy patients [11]. However, studies investigating the influence of pharmacogenetics on ROC kinetic disposition are absent. The objective of this work was to evaluate the influence of genetic polymorphisms of SLCO1A2 on the in vivo activity of OATP1A2 and the resulting alterations on the pharmacokinetics of ROC. This work was addressed to identify the potential covariates to the kinetic disposition of ROC. This clinical investigation included only ASA I-III patients undergoing elective surgery under general anesthesia using the ROC as neuromuscular blocker.

\section{Methods}

\section{Patients}

Eligible subjects $(n=35)$ were adult patients scheduled to undergo small-medium sized elective surgeries under general anesthesia and classified as class I-III according to the ASA classification. All patients were recruited at the Surgical Centre of the Clinical Hospital of the School of Medicine of Ribeirão Preto, USP. Estimated glomerular filtration rate (eGFR) was estimated from serum creatinine values using CKD-EPI equation [12]. All patients taking fluoxetine, carbamazepine, aminoglycoside antibiotics (gentamicin, amikacin, neomycin, streptomycin, tobramycin), or OATP1A2 inhibitors such as rifampicin and verapamil were excluded due to potential pharmacokinetic interaction with $\operatorname{ROC}[10,13,14]$.
Patients with impaired liver function or eGFR $<30 \mathrm{~mL} / \mathrm{min}$ were excluded from this study.

\section{Clinical protocol}

All patients scheduled for elective surgery attended the surgical center after 12-h fasting. On arrival in the operating room, two 20-gauge cannulas were inserted into peripheral veins in opposite limbs, one for drug administration and other for blood collection. All patients included in this study received intravenous (i.v.) midazolam as pre-anesthetic medication and were slowly induced with 1 to $3 \mathrm{mg} / \mathrm{kg}$ intravenous (i.v.) propofol. Fentanyl (2-3 $\mu \mathrm{g} / \mathrm{kg}$ i.v.) was then administered. Patients received a single intravenous dose $0.3-0.9 \mathrm{mg} / \mathrm{kg}$ of ROC (Esmeron®, Organon, Schering-Plough, São Paulo, SP, Brazil) for muscle relaxation. Patients were monitored during surgery including continuous blood pressure measure, pulse oximetry, central and peripheral temperature, and electrocardiography. The neuromuscular blockade was monitored using the train of four (TOF) response of the adductor pollicis muscle resulting from stimulation of the ulnar nerve $(2 \mathrm{~Hz}$ for $2 \mathrm{~s}$, TOF-Watch® SX Monitor, Organon Ireland Ltd., Swords, Ireland).

Before the surgical procedure, whole blood samples ( $4 \mathrm{~mL})$ were collected using EDTA as anticoagulant for DNA extraction. For the pharmacokinetics analysis, blood samples $(4 \mathrm{~mL})$ were collected at times $0,2,5,10,15,20,30,60,120,180$, 240 , and $360 \mathrm{~min}$ after ROC administration. Blood samples were collected into heparin-containing tubes and then centrifuged at $3220 \times \mathrm{g}$ for $10 \mathrm{~min}$ at $4{ }^{\circ} \mathrm{C}$. All plasma samples were added to $0.2 \mathrm{~mL}$ of 1-M monobasic sodium phosphate solution per each $1 \mathrm{~mL}$ of plasma to avoid hydrolysis of ROC [15, 16]. Plasma samples were stored at $-20{ }^{\circ} \mathrm{C}$ until analysis.

\section{Analysis of ROC in plasma by LC-MS/MS}

ROC was analyzed in human plasma by LC-MS/MS according to the method developed and validated by this research group [17]. ROC and verapamil, used as internal standard, were resolved in a reverse phase LiChrospher® 100 RP-18e Sorbent $(125 \times 4 \mathrm{~mm}, 5 \mu \mathrm{m}$; Merck, Darmstadt, Germany) and mobile phase constituted by mixture of water:acetonitrile:trifluoracetic acid (50:50:0.1, v/v) at $1.0 \mathrm{~mL} / \mathrm{min}$. The protonated molecular ions $[\mathrm{M}+\mathrm{H}]^{+}$and their product ions were monitored at $\mathrm{m} / \mathrm{z}$ transitions $529>487$ for ROC and $455>165$ for the internal standard (verapamil).

Samples of $120 \mu \mathrm{L}$ of the mixture plasma: $1 \mathrm{M}$ monobasic sodium phosphate buffer 5:1 $v / \nu$ (corresponding to $100 \mu \mathrm{L}$ plasma) were added to $1 \mathrm{M}$ phosphate buffer $(50 \mu \mathrm{L}), 25 \mu \mathrm{L}$ of internal standard solution (verapamil $1 \mu \mathrm{g} / \mathrm{mL}$ ), $100 \mu \mathrm{L}$ of a saturated solution of potassium iodide, and $2 \mathrm{~mL}$ of dichloromethane. After $30 \mathrm{~min}$ of reciprocating mechanical shaking, 
samples were centrifuged for $10 \mathrm{~min}$ at $5^{\circ} \mathrm{C}(1800 \times g)$. The lower organic layer was transferred to conical tubes and evaporated to dryness. The residue was reconstituted in $100 \mu \mathrm{L}$ of mobile phase and vortexed for $10 \mathrm{~s}$. An aliquot of $50 \mu \mathrm{L}$ was injected into the chromatographic system. The lower limit of quantification was $5 \mathrm{ng} / \mathrm{mL}$, and the method was linear in the interval of 5-2000 ng/mL of plasma. The relative standard deviation and the relative error (inaccuracy) did not exceed $15 \%$.

\section{Genotyping assays}

Genomic DNA was extracted from whole blood samples by salting out procedure [18]. The single nucleotide polymorphisms (SNPs) in the coding region of SLCO1A2 404A>T, $382 \mathrm{~A}>\mathrm{T}, 559 \mathrm{G}>\mathrm{A}, 502 \mathrm{C}>\mathrm{T}, 516 \mathrm{~A}>\mathrm{C}, 833 \mathrm{delA}, 830 \mathrm{C}>\mathrm{A}$, and $41 \mathrm{~A}>\mathrm{G}$ and SNPs in the promoter region SLCO1A2 $1105 \mathrm{G}>\mathrm{A},-1032 \mathrm{G}>\mathrm{A},-715 \mathrm{~T}>\mathrm{C},-361 \mathrm{G}>\mathrm{A}$, and $-189 \_-$ 188insA were evaluated using direct nucleotide sequencing.

The polymerase chain reaction (PCR) was developed using primers 5'-CATCCACAGGCAGATTATTGAA-3' (forward) and 5'-CGGCCCTTTGACTCATTTT-3' (reverse) for 404A>T, 5'-ACTAGGGGTGCCCTGAGAAG-3' (forward) and 5'-ACCTCCAGGGGCACTAGACT-3' (reverse) for 559G >A; 5'-TAGTTGGTTGGGACCCGATA-3' (forward) and 5'-AGTACCATAGGAAGAATCGGACT-3' (reverse) for $833 \mathrm{delA}$, 5'-GGCACGTACTTGGCTTTCTT-3' (forward) and 5'-TGGAAAATAATCCCACGATTG-3' (reverse) for $-1105 \mathrm{G}>\mathrm{A},-1032 \mathrm{G}>\mathrm{A}$, and $-715 \mathrm{~T}>\mathrm{C}$; and $5^{\prime}-$ GATTTTTGAGCCTTGGTAGGG-3' (forward) and 5'CTCTTCAGGGTGTTCCAAG-3' (reverse) for $-361 \mathrm{G}>\mathrm{A}$ and -189_-188insA.

PCR reactions were performed in a final volume of $25 \mu \mathrm{L}$ with $200 \mathrm{pg}$ of DNA, $0.2 \mu \mathrm{mol} / \mathrm{L}$ of each primer, $2.5 \mu \mathrm{L}$ of $10 \times$ PCR buffer, $250 \mu \mathrm{mol} / \mathrm{L}$ dNTPs, $2 \mathrm{mmol} / \mathrm{L} \mathrm{MgCl}_{2}$, and 0.2 units/ $\mu \mathrm{L}$ Taq DNA polymerase (LGC, Cotia, SP, Brazil). PCR amplification consisted of an initial denaturation for $3 \mathrm{~min}$ at $95{ }^{\circ} \mathrm{C}$ followed by 35 cycles of denaturation at $95{ }^{\circ} \mathrm{C}$ for $30 \mathrm{~s}$, $30 \mathrm{~s}$ of annealing at $60{ }^{\circ} \mathrm{C}$, and $45 \mathrm{~s}$ of extension at $72{ }^{\circ} \mathrm{C}$. After purification by digestion EXO/SAP according to the manufacturer instructions (Fermentas, Burlington, ON, Canada), direct nucleotide sequencing was performed by ABI PRISM ABI3130 using the Big dye terminator protocol (Applied Biosystems, Foster City, CA, USA).

\section{Pharmacokinetic and statistical analysis}

Pharmacokinetic parameters were calculated based on individual curves of plasma concentration versus time. Considering that patients were treated with different doses of ROC, AUC values were normalized by dose (AUC/D) for comparison between groups. Total drug clearance from plasma (CL) was calculated by the equation: $\mathrm{CL}=$ dose / AUC.

The distribution of genotypes for each polymorphism was evaluated for deviation from Hardy-Weinberg equilibrium using chi-squared test. The pharmacokinetic data are expressed as median and interquartile range. Genotypes were compared using non-parametric tests for unpaired data (Mann-Whitney test). Total clearance of rocuronium was regressed against the potential covariates age, sex, creatinine clearance, weight, and SLCO1A2 genotypes using SPSS for Mac (v. 24; SPSS Inc., Chicago, IL, USA). A $p$ value $\leq 0.05$ was considered to indicate statistical significance.

\section{Results}

The demographic and clinical characteristics are presented in Table 1. Among the 35 eligible patients, 5 patients did not complete the study for the following reasons: genotype not determined $(n=2)$ and pharmacokinetic data collection not completed $(n=3)$. All polymorphisms genotyped were in Hardy-Weinberg equilibrium (Table 2). There were no patients with heterozygous or homozygous variants of $404 \mathrm{~A}>\mathrm{T}, 382 \mathrm{~A}>\mathrm{T}, 502 \mathrm{C}>\mathrm{T}, 833 \mathrm{del} \mathrm{A}, 830 \mathrm{C}>\mathrm{A}, 41 \mathrm{~A}>\mathrm{G}$, and $-715 \mathrm{~T}>\mathrm{C}$. Linkage disequilibrium was found between $1105 \mathrm{G}>\mathrm{A}$ and $-1032 \mathrm{G}>\mathrm{A}$ genotypes $\left(D^{\prime}=1, R^{2}=1\right.$, http:// analysistools.nci.nih.giv/Ldlink/). All patients genotyped as -/A to SLCO1A2 -189_-188InsA were also genotyped as AG for $S L C O 1 A 2-1105 \bar{G}>\mathrm{A}$ and $-1032 \mathrm{G}>\mathrm{A}$ polymorphisms. One patient genotyped as homozygous mutant (AA) to -189_188InsA was also genotyped as homozygous mutant (AA) to SLCO1A2 -1105G $>$ A and $-1032 \mathrm{G}>\mathrm{A}$. However, two patients

Table 1 Demographic and clinical characteristics of patients submitted to surgery using rocuronium as neuromuscular blocker

\begin{tabular}{ll}
\hline Parameters & Median (interquartile range) or number $(\%)$ \\
\hline Age (years) & $50(39.5-75)$ \\
Sex (male/female) & $13(43) / 17(56)$ \\
ASA classification & I $(n=17)$ \\
& II $(n=12)$ \\
Body weight $(\mathrm{kg})$ & III $(n=1)$ \\
Body mass index $\left(\mathrm{kg} / \mathrm{m}^{2}\right)$ & $25.9(24.4-28.4)$ \\
eGFR (mL/min $\left./ 1.73 \mathrm{~m}^{2}\right)$ & $82(62-91)$ \\
Rocuronium dose $(\mathrm{mg} / \mathrm{kg})$ & $0.6(0.5-0.6)$
\end{tabular}

ASA classification: American Society of Anesthesiology classification for physical status: ASA I - healthy patient, ASA II - patient with mild systemic disease, ASA III - patients with severe systemic disease, ASA IV - patient with severe disabling systemic disease, and ASA V - patient at risk for life-limiting. eGFR: glomerular filtration rate estimated using CKD-EPI equation. Data are expressed as median and the interquartile range or absolute numbers and percentiles 
Table 2 Genotype and allelic frequency of OAT1A2 polymorphisms

\begin{tabular}{|c|c|c|c|}
\hline SNP & $\begin{array}{l}\text { Genotype } \\
\text { frequency }(\%)\end{array}$ & $\begin{array}{l}\text { Allelic } \\
\text { frequency (\%) }\end{array}$ & $\begin{array}{l}\text { Hardy-Weinberg } \\
\text { equilibrium* } \\
\text { ( } p \text { value) }\end{array}$ \\
\hline$-1032 \mathrm{G}>\mathrm{A}$ & $\begin{array}{l}\mathrm{GG}=0.36 \\
\mathrm{GA}=0.61 \\
\mathrm{AA}=0.03\end{array}$ & $\begin{array}{l}\mathrm{G}=0.66 \\
\mathrm{~A}=0.34\end{array}$ & 0.17 \\
\hline$-361 \mathrm{G}>\mathrm{A}$ & $\begin{aligned} \mathrm{GG} & =0.89 \\
\mathrm{GA} & =0.11 \\
\mathrm{AA} & =0\end{aligned}$ & $\begin{aligned} \mathrm{G} & =0.95 \\
\mathrm{~A} & =0.05\end{aligned}$ & 0.96 \\
\hline$-189 \_-188 \operatorname{Ins} A$ & $\begin{array}{l}-/-=0.43 \\
-/ \mathrm{A}=0.54 \\
\mathrm{AA}=0.03\end{array}$ & $\begin{array}{l}-=0.69 \\
A=0.31\end{array}$ & 0.37 \\
\hline $516 \mathrm{~A}>\mathrm{C}$ & $\begin{array}{l}\mathrm{AA}=0.89 \\
\mathrm{AC}=0.11 \\
\mathrm{CC}=0\end{array}$ & $\begin{array}{l}\mathrm{G}=0.95 \\
\mathrm{~A}=0.05\end{array}$ & 0.96 \\
\hline $559 \mathrm{G}>\mathrm{A}$ & $\begin{aligned} \mathrm{GG} & =0.89 \\
\mathrm{GA} & =0.11 \\
\mathrm{AA} & =0\end{aligned}$ & $\begin{array}{l}\mathrm{G}=0.95 \\
\mathrm{~A}=0.05\end{array}$ & 0.96 \\
\hline$-1105 \mathrm{G}>\mathrm{A}$ & $\begin{aligned} \mathrm{GG} & =0.36 \\
\mathrm{GA} & =0.61 \\
\mathrm{AA} & =0.03\end{aligned}$ & $\begin{aligned} G & =0.66 \\
A & =0.34\end{aligned}$ & 0.17 \\
\hline
\end{tabular}

*Hardy-Weinberg equilibrium was tested by chi-squared test. The level of significance was $p \leq 0.05$

genotyped as AG for SLCO1A2 $-1105 \mathrm{G}>\mathrm{A}$ and $-1032 \mathrm{G}>\mathrm{A}$ polymorphisms were homozygous for the wild-type SLCO1A2 -189_-188InsA.

The kinetic disposition of ROC was evaluated in 30 patients undergoing elective surgery under general anesthesia. The administration of 0.3 to $0.9 \mathrm{mg} / \mathrm{kg}$ ROC resulted in median (25th-75th percentiles) AUC/D 417.6 (354.2-548.8) $(\mu \mathrm{g} / \mathrm{mL} / \mathrm{min}) /(\mathrm{mg} / \mathrm{kg})$ and total body clearance of 154.3 $(150.5-207.5) \mathrm{mL} / \mathrm{min}$.

The relationship between SLCO1A2 genetic polymorphisms and the kinetic disposition of ROC is shown in Table 3. Patients genotyped as $-\mathrm{A}$ or AA $(n=17)$ for

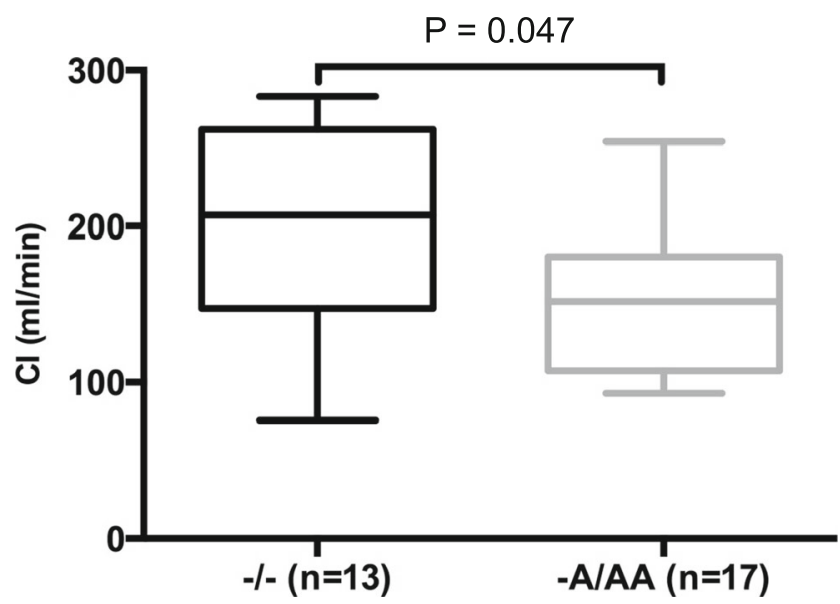

Fig. 1 Effect of SLCO1A2 -189 -188InsA polymorphism on total clearance $(\mathrm{CL})$ of rocuronium in patients undergoing elective surgery under general anesthesia. The line inside each box indicates the median; 25th and 75th percentiles are represented as the bottom and top lines of the box, respectively; error bars represent the maximum and minimum values. Groups were compared using the Mann-Whitney test for unpaired data

SLCO1A2 -189_-188InsA showed reduced total clearance of ROC compared to patients genotyped as -/$(n=13)$ (151.6 vs $207.1 \mathrm{~mL} / \mathrm{min}, p \leq 0.05)$ (Fig. 1). Patients genotyped as $-\mathrm{A}$ or AA for SLCO1A2 -189 188InsA did not differ from patients genotyped as $-\overline{-}$ $(n=13)$ in terms of rocuronium dose, age, body weight, body mass index, and serum creatinine. The pharmacokinetics parameters of ROC were not significantly different between other SLCO1A2 genotypes (Table 3).

Moderate correlation was observed between age and $\mathrm{CL}$ of ROC (correlation coefficient $=-0.520, p \leq 0.05$ ) and between SLCO1A2 -189 -188InsA genotype and Cl ROC (correlation coefficient $=-0.535, p \leq 0.05)$. A weak correlation was
Table 3 Effects of SLCO1A2 polymorphisms on rocuronium total clearance $(\mathrm{mL} / \mathrm{min})$

\begin{tabular}{|c|c|c|c|c|}
\hline \multirow[t]{2}{*}{ Polymorphism } & \multirow[t]{2}{*}{ Genotypes } & \multicolumn{2}{|c|}{ Clearance (mL/min) } & \multirow[t]{2}{*}{$p$ value } \\
\hline & & Median & 25 th -75 th percentiles & \\
\hline$-1032 /-1105 \mathrm{G}>\mathrm{A}$ & $\begin{array}{l}\text { GG }(n=8) \\
\text { GA/AA }(n=22)\end{array}$ & $\begin{array}{l}183.0 \\
154.0\end{array}$ & $\begin{array}{l}152.3-219.9 \\
108.4-199.9\end{array}$ & 0.19 \\
\hline$-361 \mathrm{G}>\mathrm{A}$ & $\begin{array}{l}\text { GG }(n=27) \\
\text { GA/AA }(n=3)\end{array}$ & $\begin{array}{l}158.8 \\
107.5\end{array}$ & $\begin{array}{l}143.0-207.4 \\
91.6-166.3\end{array}$ & 0.35 \\
\hline$-189 \_-188 \operatorname{Ins} A$ & $\begin{array}{l}-/-(n=13) \\
-\mathrm{A} / \mathrm{AA}(n=17)\end{array}$ & $\begin{array}{l}207.1 \\
151.6\end{array}$ & $\begin{array}{l}150.5-256.7 \\
107.168 .2\end{array}$ & $0.047 *$ \\
\hline $516 \mathrm{~A}>\mathrm{C}$ & $\begin{array}{l}\mathrm{AA}(n=26) \\
\mathrm{AC} / \mathrm{CC}(n=4)\end{array}$ & $\begin{array}{l}157.1 \\
147.1\end{array}$ & $\begin{array}{l}139.3-219.5 \\
120.4-167.2\end{array}$ & 0.33 \\
\hline $559 \mathrm{G}>\mathrm{A}$ & $\begin{array}{l}\mathrm{GG}(n=27) \\
\mathrm{GA} / \mathrm{AA}(n=3)\end{array}$ & $\begin{array}{l}153.2 \\
202.4\end{array}$ & $\begin{array}{l}123.2-207.4 \\
180.6-234.6\end{array}$ & 0.20 \\
\hline
\end{tabular}

*Statistically significant $(p \leq 0.05)$ 
observed between sex and CL of ROC (correlation coefficient $=-0.365, p \leq 0.05)$. Multiple regression analysis revealed that $55 \%$ of the variation in total clearance of ROC was explained by three variables: age, SLCO1A2 -189_188InsA genotype, and sex, accounting for 28.3, 16.3, and $10.4 \%$ of the variation of ROC clearance, respectively (Table 4).

\section{Discussion}

This study suggests that OATP1A2 is involved in hepatic uptake of ROC required for its elimination, which is primarily mediated by biliary excretion. The active transport of ROC into cholangiocytes is considered the determining factor for the duration of neuromuscular blocking effect, and in vitro and clinical studies have reported the important contribution of OATP1A2 for the hepatic uptake of the ROC [5-7, 19].

Genetic variation of drug transporters has important consequences for the kinetic disposition and the response of several drugs. In SLCO1A2, the non-silent single nucleotide polymorphisms (SNPs) in the coding region T38C (I13T), A516C (E172D), G559A (A187T), A382T (N128Y), A404T (N135I), and C2003G (T668S) define the allelic variants OATP 1 A $2 * 2, * 3, * 4, * 5, * 6$, and $* 7$, respectively [2]. However, clinical studies investigating the influence of SLCO1A2 polymorphisms on the kinetic disposition and drug response are still scarce [20].

The uptake of OATP1A2 substrates estrone sulfate, deltorphin II, [D-penicillamine(2,5)]-encephalin (DPDPE), and imatinib in HeLa cells was inhibited in OATP1A2*3 $(516 \mathrm{~A}>\mathrm{C})$ variant $[2,21]$. The minor allele frequency (MAF) for SLCO1A2 516A>C (OATP1A2*3) in exon 5 was $5 \%$ in our work (Table 2) and was the same found in Europeans $(5 \%)$ and in Brazilians $(5 \%)$ [2, 22]. In African, Chinese, and Hispanic populations, the MAF for SLCO1A2 $516 \mathrm{~A}>\mathrm{C}$ was $2.1,0$, and $2.1 \%$, respectively [2]. Patients with gastrointestinal stromal tumors carrying $516 \mathrm{~A}>\mathrm{C}$ (OATP1A2*3) polymorphism showed no change in imatinib kinetic disposition [21]. Likewise, in the present investigation, the presence of $516 \mathrm{~A}>\mathrm{C}(\mathrm{OATP} 1 \mathrm{~A} 2 * 3)$ polymorphism did not change the kinetic disposition of ROC in patients undergoing elective surgeries under general anesthesia.

The uptake of estrone sulfate was reduced in OATP1A2*4 $(559 \mathrm{G}>\mathrm{A})$ variant compared to the reference OATP1A2*1 [2]. In the present study, three patients were genotyped as heterozygous for $S L C O 1 A 2559 \mathrm{G}>\mathrm{A}$ (OATP1A2*4; $\mathrm{MAF}=0.05)$. However, SLCO1A2 559G $>\mathrm{A}$ polymorphism was not found previously in European, African, Chinese, or Japanese populations [2, 23]. The pharmacokinetic disposition of ROC was not altered in the presence of $559 \mathrm{G}>\mathrm{A}$ (OATP1A2*4).

The functional characterization of OATP1A2*6 (404A $>$ T) using transfected HeLa cells showed reduced uptake of estrone sulfate, deltorphin II, and [D-penicillamine $(2,5)]$ encephalin (DPDPE) compared to that of the reference [2]. Reduced OATP1A2 activity in carriers of *6 (404A $>$ T) variant is due to the reduced OATP1A2 expression $[2,24]$. In the investigation of Yamakawa et al. (2011) and in this study, none of the patients had heterozygous or homozygous variant of $404 \mathrm{~A}>\mathrm{T}(* 6)$ [23].

Inhibition of uptake of OATP1A2 substrates was also reported for the variant $* 7(2003 \mathrm{C}>\mathrm{G})$. The inhibition was $\mathrm{pH}-$ dependent with $77 \%$ reduction of uptake at $\mathrm{pH} 7.4$ and $46 \%$ reduction at $\mathrm{pH} 5$ [21]. Lee et al. (2005) suggested that reduced OATP1A2 activity in carriers of $* 7(2003 \mathrm{C}>\mathrm{G})$ variant is related to reduced OATP1A2 expression [2, 24]. The SLCO1A2 2003C>G polymorphism was not investigated in this study due to its very low frequency in Hispanic Americans (1\%) and Mexican Americans (1\%), and its absence in European Americans, Asian Americans, and Chinese Americans [2, 25].

Considering the SNPs in the promoter region, the linkage disequilibrium between SLCO1A2 -1105G $>$ A and $-1032 \mathrm{G}>\mathrm{A}$ observed in this study has been previously reported in the investigation of 34 patients with chronic myeloid leukemia (CML). The MAF for SLCO1A2 -1105G $>$ A and $-1032 \mathrm{G}>\mathrm{A}$ polymorphisms was approximately 0.3 in the investigation of 100 healthy volunteers and 34 patients with chronic myeloid leukemia [23]. Similarly, the MAF of 0.34 for SLCO1A2 $1105 \mathrm{G}>\mathrm{A}$ and $-1032 \mathrm{G}>\mathrm{A}$ polymorphisms was found in this work (Table 2). In the evaluation of imatinib clinical pharmacokinetics, no differences in drug clearance were observed in the presence of $-1105 \mathrm{G}>\mathrm{A} /$ - or $1032 \mathrm{G}>\mathrm{A}(p \geq 0.05)$.
Table 4 Multiple regression analysis to estimate the contribution of age, weight, and SLCO1A2 -189_-188InsA genotype to the clearance of rocuronium in patients submitted to elective surgeries $(n=30)$

\begin{tabular}{lll}
\hline Covariate & Contribution of covariates & $p$ value \\
\hline SLCO1A2 -189_-188InsA genotype (\%) & 16.3 & $0.002^{*}$ \\
Age (years) (\%) & 28.3 & $0.003^{*}$ \\
Sex (male = 0; female = 1) (\%) & 10.4 & $0.036^{*}$ \\
Weight $(\mathrm{kg})$ & - & 0.61 \\
$R^{2}$ & 0.585 & 0.002 \\
\hline
\end{tabular}

*Statistically significant $(p \leq 0.05)$ 
Similarly, no differences were found on ROC clearance in terms of SLCO1A2 -1105G $>$ A and $-1032 \mathrm{G}>\mathrm{A}$ genotypes (Fig. 1).

Within Japanese patients, the MAF for SLCO1A2 -189 188insA varied from 0.10 to 0.12 [23], while the MAF of 0.31 was found in this work (Table 2). In the evaluation of imatinib clinical pharmacokinetics, no differences in drug clearance were observed in the presence of -189_-188insA polymorphisms $(p \geq 0.05)$. However, our data showed that patients carrying -A/AA genotypes $(n=17)$ for SLCO1A2 -189_188insA presented significant reduction in clearance of rocuronium $(p \leq 0.05)$.

The presence of SLCO1A2 -361G $>$ A polymorphism increased significantly the clearance of imatinib in Japanese patients with chronic myeloid leukemia $(p \leq 0.05)$ [23]. On the other hand, in the investigation of Brazilian patients undergoing elective surgery under general anesthesia, SLCO1A2 $-361 \mathrm{G}>\mathrm{A}$ had no impact on ROC kinetic disposition (Fig. 1, Table 3).

Multiple regression analysis showed that age, SLCO1A2 189_-188InsA genotype, and sex accounted for 28.3, 16.3, and $10.4 \%$ of the variation of ROC clearance, respectively. Collinearity was observed between age and eGFR, which are highly correlated. Age was chosen to the final regression model because it has shown to be a better predictor than eGFR (Table 4).

\section{Conclusions}

Patients carrying -A/AA genotypes for SLCO1A2 -189_188 ins A presented significant reduction on ROC clearance. When the present findings are compared to previous literature, the different influences of SLCO1A2 -361G $>\mathrm{A}$ and SLCO1A2 -189 -188InsA polymorphisms on the pharmacokinetics of imatinib and rocuronium emphasize the importance of investigating the influence of pharmacogenetics of OATP1A2 in the clinical pharmacology of its substrates.

Acknowledgements This work was supported by the Fundação de Amparo a Pesquisa do Estado de São Paulo (FAPESP, Grant number 2013/14730-0) and Programa de Apoio ao Desenvolvimento Científico, Faculdade de Ciências Farmacêuticas - UNESP (PADC-FCF, Grant number 2013/1-I).

Authors' contributions NVM, GRL, and VLL designed this study. ACCC, EBC, and JTA performed the pharmacogenetics analysis.

ACCC, BVC, and NVM performed the pharmacokinetics and statistical calculations. ACCC and NVM wrote the manuscript. All authors approved the final version of the manuscript.

Compliance with ethical standards The study was performed in accordance with the revised Declaration of Helsinki and the Good Clinical Practice of the International Conference on Harmonization (ICH-GCP). The Ethics Committee of the School of Pharmaceutical Sciences of Ribeirão Preto and the School of Medicine of Ribeirão Preto,
University of São Paulo (USP) approved the clinical protocol on September 13th, 2012 (CAAE 02583412.2.0000.5403). All patients provided written informed consent.

\section{References}

1. Steckelbroeck S, Nassen A, Ugele B et al (2004) Steroid sulfatase (STS) expression in the human temporal lobe: enzyme activity, mRNA expression and immunohistochemistry study. J Neurochem 89:403-417. doi:10.1046/j.1471-4159.2004.02336.x

2. Lee W, Glaeser H, Smith LH et al (2005) Polymorphisms in human organic anion-transporting polypeptide 1A2 (OATP1A2): implications for altered drug disposition and central nervous system drug entry. J Biol Chem 280:9610-9617. doi:10.1074/jbc.M411092200

3. Glaeser H, Bailey DG, Dresser GK et al (2007) Intestinal drug transporter expression and the impact of grapefruit juice in humans. Clin Pharmacol Ther 81:362-370. doi:10.1038/sj.clpt.6100056

4. Obaidat A, Roth M, Hagenbuch B (2011) The expression and function of organic anion transporting polypeptides in normal tissues and in cancer. Annu Rev Pharmacol Toxicol 7:135-151. doi:10. 1146/annurev-pharmtox-010510-100556

5. Olinga P, Merema M, Hof IH et al (1998) Characterization of the uptake of rocuronium and digoxin in human hepatocytes: carrier specificity and comparison with in vivo data. J Pharmacol Exp Ther 285:506-510

6. van Montfoort JE, Hagenbuch B, Fattinger KE et al (1999) Polyspecific organic anion transporting polypeptides mediate hepatic uptake of amphipathic type II organic cations. J Pharmacol Exp Ther 291:147-152

7. Proost JH, Eriksson LI, Mirakhur RK, Roest G, Wierda JM (2000) Urinary, biliary and faecal excretion of rocuronium in humans. Br J Anaesth 85:717-723

8. Roy JJ, Varin F (2004) Physicochemical properties of neuromuscular blocking agents and their impact on the pharmacokineticpharmacodynamic relationship. Br J Anaesth 93:241-248. doi:10. 1093/bja/aeh181

9. Kleijn HJ, Zollinger DP, van den Heuvel MW, Kerbusch T (2011) Population pharmacokinetic-pharmacodynamic analysis for sugammadex-mediated reversal of rocuronium-induced neuromuscular blockade. Br J Clin Pharmacol 72:415-433. doi:10.1111/j. 1365-2125.2011.04000.x

10. Staals LM, Snoeck MM, Driessen JJ et al (2010) Reduced clearance of rocuronium and sugammadex in patients with severe to endstage renal failure: a pharmacokinetic study. $\mathrm{Br} \mathrm{J}$ Anaesth 104: 31-39. doi:10.1093/bja/aep340

11. van Miert MM, Eastwood NB, Boyd AH, Parker CJ, Hunter JM (1997) The pharmacokinetics and pharmacodynamics of rocuronium in patients with hepatic cirrhosis. Br J Clin Pharmacol 44:139-144

12. Levey AS, Stevens LA, Schmid CH et al (2009) A new equation to estimate glomerular filtration rate. Ann Intern Med 150:604-612

13. Spacek A, Neiger FX, Krenn CG, Hoerauf K, Kress HG (1999) Rocuronium-induced neuromuscular block is affected by chronic carbamazepine therapy. Anesthesiology 90:109-112

14. Patel JC, Barvaliya MJ, Patel TK, Tripathi CB (2013) Neuromuscular blocking effect of fluoxetine and its interaction with rocuronium. Auton Autacoid Pharmacol 33:17-24. doi:10. 1111/aap. 12005

15. Gutteck-Amsler U, Rentsch KM (2000) Quantification of the aminosteroidal non-depolarizing neuromuscular blocking agents rocuronium and vecuronium in plasma with liquid chromatography-tandem mass spectrometry. Clin Chem 46:14131414 
16. Kleef UW, Proost JH, Roggeveld J, Wierda JM (1993) Determination of rocuronium and its putative metabolites in body fluids and tissue homogenates. J Chromatogr 621:65-76

17. De Moraes NV, Lauretti GR, Lopes BCP, Filgueira GCO, Lanchote VL (2014) Analysis of rocuronium in human plasma by liquid chromatography-tandem mass spectrometry with application in clinical pharmacokinetics. J Pharm Biomed Anal 90:180-185. doi:10.1016/j.jpba.2013.11.032

18. Miller SA, Dyker DD, Polesky HF (1988) A simple salting out procedure for extracting DNA from human nucleated cells. Nucleic Acids Res 16:1215

19. Sandker GW, Weert B, Olinga P et al (1994) Characterization of transport in isolated human hepatocytes. A study with the bile acid taurocholic acid, the uncharged ouabain and the organic cations vecuronium and rocuronium. Biochem Pharmacol 47:2193-2200

20. Franke RM, Scherkenbach LA, Sparreboom A (2009) Pharmacogenetics of the organic anion transporting polypeptide 1A2. Pharmacogenomics 10:339-344. doi:10.2217/14622416.10. 3.339
21. Eechoute K, Franke RM, Loos WJ et al (2011) Environmental and genetic factors affecting transport of imatinib by OATP1A2. Clin Pharmacol Ther 89:816-820. doi:10.1038/clpt.2011.42

22. Bonifaz-Peña V, Contreras AV, Struchiner CJ et al (2014) Exploring the distribution of genetic markers of pharmacogenomics relevance in Brazilian and Mexican populations. PLoS One 9:1-22. doi:10. 1371/journal.pone.0112640

23. Yamakawa Y, Hamada A, Shuto T et al (2011) Pharmacokinetic impact of SLCO1A2 polymorphisms on imatinib disposition in patients with chronic myeloid leukemia. Clin Pharmacol Ther 90: 157-163. doi:10.1038/clpt.2011.102

24. Kalliokoski A, Niemi M (2009) Impact of OATP transporters on pharmacokinetics. Br J Pharmacol 158:693-705. doi:10.1111/j. 1476-5381.2009.00430.x

25. Badagnani I, Castro RA, Taylor TR et al (2006) Interaction of methotrexate with organic-anion transporting polypeptide $1 \mathrm{~A} 2$ and its genetic variants. J Pharmacol Exp Ther 318:521-529. doi: 10.1124/jpet.106.104364 